\title{
REGIMES JURÍDICOS E OS POVOS DA FLORESTA: UM BREVE BALANÇO DA APLICAÇÃ̃O DE REGIMES JURÍDICOS INTERNACIONAIS NA PROTEÇÃ̉O DE COMUNIDADES INDÍGENAS
}

\section{LEGAL REGIMES AND THE FOREST PEOPLE: A BRIEF REVIEW OF THE IMPLEMENTATION OF INTERNATIONAL LEGAL REGIMES FOR THE PROTECTION OF INDIGENOUS COMMUNITIES}

${ }^{1}$ Janaina Nascimento Silva

\section{RESUMO}

O presente artigo tem como objetivo identificar os regimes jurídicos internacionais aplicáveis às populações indígenas. Assim, procura-se deixar claro que existem normas internacionais destinadas para a proteção e reparação de tais povos, e que essas normas estão associadas, não só a regimes jurídicos distintos, como também impactam no estabelecimento de uma correlação entre Direito e Desenvolvimento.

Palavras-chave: Regimes internacionais, Desenvolvimento, Comunidades indígenas, Fragmentação

\begin{abstract}
This article aims to identify the international legal regimes applicable to the indigenous population. Therefore, this article seeks to make clear that some international norms were designed for the protection and repair of such communities, and that these norms are associated not only to distinct legal systems, as well that they impact at the establishment of a correlation between Law and Development.
\end{abstract}

Keywords: International regimes, Development, Indigenous communities, Fragmentation

\footnotetext{
${ }^{1}$ Mestranda em Direito e Desenvolvimento e pesquisadora pela Fundação Getúlio Vargas - FGV, São Paulo (Brasil) E-mail: nascimento.janaina.silva@gmail.com
} 


\section{INTRODUÇÃO}

Partindo-se do pressuposto de que o estudo dos "Regimes Internacionais no Contexto do Desenvolvimento" se propõe a avaliar a dupla "Direito e Desenvolvimento" a partir de um ângulo específico, através do qual compreende-se o Direito como um conjunto de normas, instituições e regulação capaz de operar no espaço internacional ou transnacional, nas relações entre os Estados e também nas relações que envolvem outros entes através das fronteiras, compreende-se que a lei deve ser considerada como um assunto prático que requer conhecimento local com foco em questões específicas e bem definidas (TWINING, 2009).

Com este conceito em mente, a preocupação com uma definição para o Direito Internacional se torna mais complexa, pois inserido em um contemporâneo contexto de universalização e fragmentação, o conceito de direito internacional precisa ser capaz de abarcar não só o seu campo de atuação, como seus atores e sujeitos modernos. Assim, visando abarcar essas noções, o presente trabalho estará dividido em três partes.

A parte 1 apresenta um panorama da noção de fragmentação do Direito Internacional, bem como, a contemporânea discussão do direito internacional sobre tal conceito. Nesse sentido, a parte 2 busca sinteticamente analisar a aplicação dos regimes jurídicos oriundos do processo de fragmentação na proteção dos povos da floresta.

Por fim, a parte 3 se preocupa com relacionar o desenvolvimento, seja em seu viés étnico, econômico ou sustentável, como uma ferramenta para a promoção da proteção de comunidades tradicionais, por se compreender que o desenvolvimento quando afeta povos indígenas deverá equacionar as perspectivas econômicas, sociais, ambientais e culturais.

A partir do que foi mencionado, a metodologia empregada para o desenvolvimento deste trabalho foi a de pesquisa bibliográfica qualitativa, que objetivou através do levantamento bibliográfico sobre as temáticas aqui abarcadas, proceder com uma leitura analítica da doutrina, artigos científicos e documentos disponibilizados sobre a temática de proteção dos povos indígenas, para que se tornasse possível responder ao seguinte questionamento: até que ponto a atual fragmentação do direito internacional também abarca os povos indígenas?

A elaboração do desenvolvimento e conclusão que serão aqui apresentados, procurará responder a esse questionamento. Destaque para o fato de que os comparativos feitos ao longo da exposição com a construção do projeto de infraestrutura da Usina Hidroelétrica de Belo Monte, não pretendem, em nenhum momento, exaurir as possibilidades de correlações que a temática "fragmentação do direito internacional" possui com a questão indígena. Trata-se 
apenas de uma opção acadêmica para se melhor ilustrar a aplicação prática da questão aqui em discussão.

\section{A FORMAÇÃO DA FRAGMENTAÇÃO NO CAMPO DO DIREITO}

INTERNACIONAL: um panorama geral da concepção de regimes jurídicos

Dotado de um conjunto normativo obrigatório e com poderes de sanção, o Direito Internacional constitui-se sinteticamente por um conjunto de regras e princípios que são responsáveis pela regulação da sociedade internacional. Tal sociedade é composta por diferentes atores como os Estados e Organizações Internacionais, e passou a abarcar mais recentemente, em diferentes níveis, “a participação de entes com algumas características estatais, [...] além de outros atores, como indivíduos, empresas, organizações não governamentais." (VARELLA, 2012)

Essa expansão de sujeitos ativos do direito internacional, também refletiu na expansão do campo de atuação desse ramo do direito. Em documento elaborado pelas Nações Unidas, "Fragmentation of International Law: difficulties arising from the diversification and expansion of International Law", constata-se que o Direito Internacional não mais se limita ao tratamento de questões relativas a diplomacia. Atualmente, inclui-se no seu escopo discussões sobre relações comerciais, proteção ambiental, direitos humanos, cooperação científica e tecnológica.

A especialização do Direito Internacional, através da qual se criam conjuntos normativos organizados em torno de áreas especificas, que compreendem ao mesmo tempo um sistema jurídico unificado e coerente, acaba por sintetizar a atual forma de organização do direito internacional. A fragmentação, passa então a ser considerada como um resultado do processo de expansão, e especialmente especialização que resulta na "emergência de regras especializadas e (relativamente) autônomas ou complexos de normas, instituições legais e esferas de prática jurídica"1 (ONU, 2006, p. 3).

Como consequência, a noção de fragmentação, seja ela normativa ou institucional, também passa a ser compreendida a partir de uma perspectiva dual. Para alguns, sua existência é responsável pela formação de problemas e dificuldades, como uma "erosão do direito internacional geral, emergência de jurisprudência conflituosa, fórum-shopping e perda de

1 Do original: "[...] emergence of specialized and (relatively) autonomous rules or rule-complexes, legal institutions and spheres of legal practice" (ONU, 2006, p. 3). Tradução livre. 
segurança jurídica"² (ONU, 2006, p. 4). Para outros, a fragmentação decorrente da especialização não passa de uma demonstração expressa da evolução do Direito Internacional, que não poderia se manter inerte diante do crescimento da atividade legal no âmbito internacional.

Para a Organização das Nações Unidas, no relatório apresentado pelo "Study Group of the International Law Commission", a figura da fragmentação poderá ser apresentada através de três situações conflituosas:

a. Fragmentação através de interpretação conflituosa da lei geral;

b. Fragmentação através do surgimento de lei especial como uma exceção à lei geral; e

c. Fragmentação como uma diferenciação entre tipos de lei especial. ${ }^{3}$

Todos esses casos representam sinteticamente como a fragmentação pode ser delineada. Enquanto na primeira situação, a fragmentação trata do conflito na interpretação de normas gerais e seus efeitos de acordo com diferentes interpretações legais, a segunda e terceira situação tratam de ocasiões em que a lei, e não interpretações, se apresenta de maneira diferenciada de acordo com o quadro normativo que é usado.

Nesse sentido:
A justificativa para o tratamento da Comissão sobre a fragmentação é que o surgimento de leis novas e especiais, "regimes autocontidos" e tratados- sistemas geograficamente ou funcionalmente limitados, cria problemas de coerência no âmbito do direito internacional. Novos tipos de direito especializado não surgem acidentalmente, mas procuram responder a novos requisitos técnicos e funcionais. ${ }^{4}$ (ONU, 2006, p. 14)

A emergência de um conjunto normativo focado em áreas e problemas específicos, como já se percebeu, decorre de uma necessidade apresentada pelo panorama jurídico internacional. Para complementar esse entendimento, surge a necessidade de se apresentar outro conceito jurídico internacional.

\footnotetext{
${ }^{2}$ Do original: "[...] "erosion of general international law, emergence of conflicting jurisprudence, forum-shopping and loss of legal security” (ONU, 2006, p. 4). Tradução livre.

${ }^{3}$ Do original: "a. Fragmentation through conflicting interpretations of general law; Fragmentation through the emergence of special law as exception to the general law; e c. Fragmentation as differentiation between types of special law.” Tradução livre.

${ }^{4}$ Do original: "The rationale for the Commission's treatment of fragmentation is that the emergence of new and special types of law, "self-contained regimes" and geographically or functionally limited treaty-systems creates problems of coherence in international law. New types of specialized law do not emerge accidentally but seek to respond to new technical and functional requirements" (ONU, 2006, p. 14). Tradução livre.
} 
Considerado como um dos produtos da fragmentação, os regimes jurídicos ou regimes autocontidos (self-contained regimes), para o direito internacional público, serão compreendidos como conjuntos normativos organizados em torno de temas ou áreas específicas, ou ainda, como um sistema complexo de normas e estruturas organizacionais destinadas a regulação de determinado tema (NASSER, 2012).

Tendo esse conceito em mente, a parte seguinte do presente artigo buscará apresentar como a existência de regimes jurídicos, decorrentes da fragmentação, impactaram na regulação jurídica internacional voltada para comunidades tradicionais, sobretudo os povos indígenas.

\section{A PERSPECTIVA SOCIOECONÔMICA AMBIENTAL DO DIREITO}

INTERNACIONAL: delimitação dos regimes jurídicos aplicáveis aos povos da floresta

Contemporaneamente, a fragmentação da sociedade refletiu na fragmentação do direito internacional. A formação de regimes jurídicos, ou sub-regimes que irão compor o regime do direito internacional, está diretamente relacionada com o comportamento paradoxo ocasionado pelo fenômeno da globalização.

Ao mesmo tempo em que se permitiu um aumento na uniformização da vida social de uma forma global, existiu um aumento no processo de fragmentação. Formam-se densas redes que permitem a sobreposição de diversas áreas temáticas. E, é nesse sentido, que se compreende que:

Dentro de um regime jurídico, fronteiras geográficas foram substituídas por delimitações funcionais, sistêmicas: 'a diferença nacional de normas é agora sobreposta pela fragmentação estrutural'. Se toda lei internacional necessariamente segue a lógica de uma específica área com uma problemática, não há surpresa no estabelecimento de 'regimes autocontidos genuínos' $[. . .]^{5}$ (SIMMA, PULKOWSKI, 2006)

A definição de regimes especiais pode ser feita através da delimitação dos três tipos especiais de regimes jurídicos autocontido que são possíveis ${ }^{6}$. Contudo, para o presente estudo,

\footnotetext{
${ }^{5}$ Do original: "Within the legal system, geographical borders have been replaced by functional, systemic delimitations: 'the national differentiation of law is now overlain by structural fragmentation'. If all international law necessarily follows the logic of a particular issue area, it comes as no surprise that the establishment of 'genuinely selfcontained regimes' appears conceivable” (SIMMA, PULKOWSKI, 2006). Tradução livre.

${ }^{6} \mathrm{O}$ documento "Fragmentation of International Law: difficulties arising from the diversification and expansion of International Law" apresenta três tipos de regimes especiais a serem distinguidos:

a. Regime especial formado quando normas primárias são acompanhadas de normas secundárias, e, portanto, especiais, diretamente relacionadas com a violação ou reação a violação das normas primárias.

b. Regime especial formado pelo estabelecimento de leis especiais, incluindo direitos e obrigações que se referem a um assunto especifico, dentro de uma determinada área geográfica ou matéria substantiva.
} 
somente uma dessas possibilidades terá destaque. Assim sendo, os regimes especiais que derivam da reunião de normas e princípios destinados a regulação de uma certa área temática, e são compostos por normas referentes a um objeto e objetivo específico, estreitando a regulação que pode ser estabelecida por normas gerais do direito internacional, são de fundamental importância quando se lida com a temática de proteção de direitos de comunidades tradicionais.

Tais direitos são focados em uma proteção mais específica, e considerando que comunidades indígenas têm salvaguardado o direito de organização de sua cultura, hábitos, costumes, tradições, organização social, linguagem e crenças, dois regimes jurídicos especiais assumem esse papel de relevante importância: o direito ambiental internacional e os direitos humanos.

Compreende-se que a proteção de povos indígenas está diretamente relacionada com o desenvolvimento de "self-contained regimes", ou seja, elaboram-se regimes ligados a temática de proteção dos Direitos Humanos, tratando aqui especificamente de comunidades tradicionais, e abarca ainda, o regime especial do Direito Ambiental, por se compreender que diante do expressivo crescimento sobre a temática de preservação ambiental, a atuação dos povos da floresta não poderá ser deixada de lado.

3.1 O regime jurídico do Direito Ambiental Internacional e sua relação com a proteção de direitos indígenas

Desenvolvido com base no entendimento de que problemas ambientais não reconhecem a existência de uma fronteira, nem se confinam ao território de um Estado, o Direito Ambiental Internacional assume como responsabilidade a elaboração de um corpo específico de normas internacionais (direitos e obrigações) voltados para a proteção do direito ambiental.

Destinados aos Estados, organizações governamentais internacionais e indivíduos da sociedade que promovem a defesa do meio ambiente, segundo Birnie e Boyle, autores da obra "International Law and the Environment", o Direito Ambiental Internacional possui quatro papéis específicos:

c. Regime especial formado quando normas e princípios se reúnem para regular determinado assunto. Aqui, abarcam-se regimes como: direito humanitário, direitos humanos, direito ambiental, direito do comércio e trocas, direito do mar, entre outros variados regimes jurídicos especiais. 
a. Prover mecanismos e procedimentos para negociar as regras e padrões necessários, resolver disputas e supervisionar a implementação e adequação aos tratados e regras costumeiras. Ajudar, pois, a promover a cooperação entre Estados, organizações internacionais, e ONGs (organizações não-governamentais).

b. Regulamentar problemas ambientais, estabelecer padrões e objetivos internacionais comuns para a prevenção ou redução do dano, e prover um processo e elaboração de regras flexível que permite a adaptação rápida a novos desenvolvimentos tecnológicos e avanços científicos.

c. Estabelecer reparação ou compensação por dano ambiental sofrido por um Estado ou indivíduo em virtude de dano transfronteiriço.

d. Harmonizar leis nacionais, tanto em âmbito global como em âmbito regional (União Europeia, por exemplo), posto que os tratados e outros instrumentos internacionais acabam inspirando a elaboração de leis internas em diversos países.

O presente trabalho seguirá a linha de raciocínio apresentada pelo doutrinador Antonio Augusto Cançado Trindade na obra "Environment and Development: Formulation and implementation of the Right to Development as a Human Right"7. Compreende-se que o direito ao meio ambiente sadio não pode ser visto de maneira isolada, pois, o mesmo está integralmente ligado ao direito ao desenvolvimento, e mais precisamente, ao princípio contemporâneo do direito internacional, conhecido como princípio do desenvolvimento sustentável.

Deste modo, inserido no debate da "Nova Ordem Mundial", ou como alguns doutrinadores apontam, "Nova Ordem Ambiental Internacional"8, esse regime jurídico do Direito Ambiental Internacional reflete a necessidade de conscientização acerca das questões ambientais por parte da comunidade internacional.

O que se busca não é somente a proteção do meio ambiente, como um conjunto dinâmico e interativo. $\mathrm{O}$ que se pretende, na verdade, é a promoção de uma proteção para o próprio ser humano, tendo em mente que a garantia de um meio ambiente sadio impacta diretamente na conservação e bem-estar humano.

No caso de comunidades tradicionais, a direito ambiental estará correlacionado com a promoção da proteção do direito de propriedade desses povos. Ao passo que terra e territórios

\footnotetext{
${ }^{7} \mathrm{O}$ mencionado trabalho acadêmico é um capítulo da obra organizada por Antonio Augusto Cançado Trindade denominada "Derechos humanos, desarrollo sustentable y meio ambiente", publicado no ano de 1992.

${ }^{8}$ Fernando Rei, no livro "Direito Internacional do Meio Ambiente" apresenta concepção de que: "Esse movimento que progressiva, adequada e efetivamente abre caminho à participação dos atores principais e secundários das relações internacionais nos processos de elaboração, harmonização e aplicação das normas comuns do Direito Internacional, até conseguir um novo pacto de legitimidade global à luz de uma Nova Ordem Ambiental Internacional. Aí então será possível pensar seriamente num governo da biosfera” (REI, 2006, p. 13)
} 
possuem elevada importância para a conservação do diferenciado modo de vida indígena, tornou-se necessário o desenvolvimento de alguns mecanismos internacionais de proteção ambiental que assumem essa reponsabilidade de proteção da propriedade.

Assim, sem possuir a intenção de exaurir as possibilidades em que as normas de direito internacional também abarcam a proteção do direito de propriedade de indígena, o documento "State of the World's Indigenous Peoples" apresentado pelas Nações Unidas, designa os seguintes documentos como partes do regime jurídico internacional de proteção do direito ambiental:

a. A Declaração da Conferência das Nações Unidas sobre o Meio Ambiente Humano, também conhecida como Declaração de Estocolmo, de 1972. Essa declaração que já buscava conciliar desenvolvimento econômico com medidas de conservação ambiental, previa que caberia aos Estados assumirem a responsabilidade pelos prejuízos decorrentes de danos ambientais, o que também já demonstrava a noção de que projetos que gerassem deslocamento ou reassentamentos forçados, não eram projetos ideais para gerar o máximo de benefícios sociais, econômicos e ambientais.

b. "World Charter for Nature" elaborado em que 1982. Tal instrumento buscava estabelecer o entendimento de que a exploração da natureza deveria sempre ser pautada em critérios de proporcionalidade.

b. Declaração do Rio sobre Meio Ambiente e Desenvolvimento de 1992, composta ainda pela Agenda 21 e pelos princípios para a administração sustentável das Florestas. Essa declaração estabelecia a obrigação de reparar dos Estados, no caso da ocorrência de danos ambientais, cabendo a avaliação prévia dos impactos, antes da efetiva realização dos projetos de desenvolvimento

c. Convenção sobre a Diversidade Biológica (CBD).

d. Convenção-Quadro sobre Mudança do Clima (UNFCCC).

e. Cupula Mundial sobre Desenvolvimento Sustentável ou United Nations World Summit on Sustainable Development (WSSD).

Todos esses documentos acabam por impactar, direta ou indiretamente, na proteção de comunidades indígenas que se veem ameaçadas por projetos de infraestrutura. Ainda assim, o que se encontra na atual realidade apresentada pelos Estados é a seguinte situação: 
Esse emergente padrão de conflitos em território indígena é um indicativo de três tendências interligadas: primeiro, povos indígenas se tornam cada vez mais as vítimas de um abuso sistemático associado com as formas com que $\mathrm{o}$ desenvolvimento econômico é imposto; segundo, povos indígenas estão se organizando em nível global, regional, nacional e local para resistir as esses modelos externos de desenvolvimento que lhe são impostos; terceiro, esses modelos de desenvolvimento e o processo pelo qual eles são impostos para povos indígenas constituem uma das formas com que a globalização econômica é gerenciada e controlada. ${ }^{9}$ (DOYLE, GILBERT, 2010, grifo nosso)

Um exemplo que demonstra a aplicabilidade das supramencionadas considerações, é o fato de que tal realidade, por exemplo, não seria diferente com as comunidades afetadas pela construção da Usina Hidroelétrica de Belo Monte. Afetadas pelo desenvolvimento econômico a ser promovido pelo aproveitamento energético, considerado como essencial para suprir as necessidades do país, os supramencionados documentos, demostram como as disposições normativas do direito internacional, organizadas em diferentes níveis (global, regional e nacional), poderão impactar na forma com o judiciário brasileiro está tomando, ou ainda, virá a tomar as decisões referentes a reparação do direito de propriedade indígena e recuperação ambiental, naquilo que for possível, diante dos incomensuráveis impactos que estão sendo produzidos pela obra em questão.

3.2 O regime jurídico dos Direitos Humanos e sua relação com a proteção de direitos indígenas

Direitos Humanos em sua concepção contemporânea devem ser compreendidos como uma "unidade indivisível, interdependente e inter-relacionada, na qual os valores de igualdade e liberdade se conjugam e se completam" (PIOVESAN, 2013).

Baseando-se nessa premissa, a proteção de povos indígenas é regida com um extenso conjunto normativo no direito internacional, que “[...] vem com os seus próprios princípios, com a sua própria forma de conhecimento e com seu próprio ‘ethos’[...]”10 (ONU, 2006, p. 5). Para tanto, dentre os instrumentos jurídicos apresentados internacionalmente sobre a questão indígena, e que se inserem no regime de direitos humanos, é possível elencar por exemplo: a Declaração das Nações Unidas sobre os Direitos dos Povos Indígenas; a Convenção n. 107 da

\footnotetext{
${ }^{9}$ Do original: "This emerging pattern of conflicts in indigenous territories is indicative of three interrelated trends: first, indigenous peoples are increasingly the victims of systematic abuse associated with imposed forms of economic development; second, indigenous peoples are organizing at the global, regional, national and local levels to resist these externally imposed development models; third, these models of development and the process by which they are imposed on indigenous peoples are a function of the manner in which economic globalization is managed and controlled." (DOYLE, GILBERT, 2010). Tradução livre.

${ }^{10}$ Do original: “““[...] comes with its own principles, its own form of expertise and its own 'ethos' [...]” (ONU, 2006, p. 5). Tradução livre.
} 
Organização Internacional do Trabalho (OIT); a Convenção n. 169 da Organização Internacional do Trabalho (OIT); e a Declaração Americana sobre os Direitos dos Povos Indígenas.

Entre esses documentos, a aplicação da Convenção n. 169 da OIT tornou-se responsável por delimitar a questão da proteção para as comunidades indígenas, estabelecendo padrões de interpretação e direitos humanos fundamentais para estes povos, mantendo-se a necessidade de participação das comunidades tradicionais na elaboração de projetos de desenvolvimento que irão afetar sua sobrevivência cultural. Trata-se de uma forma de compatibilizar os interesses do desenvolvimento econômico com os interesses tradicionais, cabendo ao governo que proceda com a realização de estudos sobre os impactos que poderão acontecer no meio ambiente ocupado.

Já a Declaração das Nações Unidas sobre os Direitos dos Povos Indígenas, aprovada em 2007, busca complementar as disposições voltadas para a proteção e promoção dos direitos dos povos indígenas. Em seu preâmbulo, demonstra-se a preocupação que se teve, no momento de sua elaboração, em se considerar as injustiças históricas perpetradas contra as comunidades tradicionais, provenientes “[...] da colonização e da subtração de suas terras, territórios e recursos, o que lhes tem impedido de exercer, em especial, seu direito ao desenvolvimento, em conformidade com suas próprias necessidades e interesses[...]”.

Além dos instrumentos elencados, existem algumas orientações que podem ser encontradas no campo do direito internacional, sendo uma delas as Diretrizes Akwé: Kon. Essas diretrizes foram criadas para complementar os ensinamentos da Convenção da Diversidade Biológica (CDB), e devem ser usadas como guias para o desenvolvimento e implantação de projetos de grande porte, que podem afetar sítios sagrados, terras e águas de comunidades indígenas e comunidades locais.

Tais normas, podem ser trazidas para o contexto nacional. Para os povos Arara, Juruna e Xikrin, afetados direta ou indiretamente pela construção da Usina Hidroelétrica de Belo Monte, essas normas seriam balizadoras das medidas de mitigação e reparação que estão (ou deverão) sendo ofertadas pelo poder público.

O que se quer dizer aqui é que, a proteção nacional baseada somente nas ultrapassadas disposições do Estatuto do Índio, ou nas simples disposições da Constituição Federal, não poderão estabelecer parâmetros mínimos para a consolidação de uma efetiva reparação. Mais uma vez, as disposições do regime jurídico internacional, ao se demonstrarem mais vantajosas, se empregadas pelo judiciário nacional, poderiam ampliar o escopo de proteção dos povos indígenas brasileiros. 
Cumpre ressaltar, que no caso de sua violação do direito de propriedade indígena, as disposições do regime jurídico internacional de Direitos Humanos, como já bem se compreendeu, se aplicam para comunidades indígenas, inclusive no caso de povos que possuem seus direitos afetados por situações como a promoção de projetos de infraestrutura. Tais projetos, conforme determinação da Corte Interamericana de Direitos Humanos, são aqueles que buscam aumentar ou melhorar a produtividade ou a infraestrutura pública, incluindo a construção de represas (OEA, 2010).

Mantendo o exemplo da UHE de Belo Monte, seus impactos irão exigir que o judiciário brasileiro tenha conhecimento de como o regime jurídico dos direitos humanos atua quando se tem na balança direito de desenvolvimento econômico e direito de povos e populações tradicionais. Para que se tenha uma efetiva proteção desses povos, sempre considerando que os mesmos mantêm uma relação extremamente especial entre si, bem como, com o ambiente que ocupam, existem algumas características específicas que devem ser consideradas.

Quando se trata da relação entre comunidades indígenas, a proteção do direito internacional já acalcou o conhecimento de que as violações aos direitos humanos atingem, nesse caso, não só indivíduo e sim a comunidade de maneira integral. A própria Corte Interamericana já considerou no Caso da Comunidade Moiwana vs. Suriname, que a relação que se tem com o território não se centra no indivíduo e sim na comunidade como um todo, sendo importante ressaltar a relação "omnicompreensiva" que se possui com as terras tradicionais ${ }^{11}$. Desse modo, a interpretação quando se trata de questões como as possíveis reparações para os direitos humanos, como seus direitos a etnodesenvolvimento, livre disposição de seus recursos, consulta, consentimento e repartição de benefícios, não poderia ser realizada de maneira diferente, devendo também, abarcar a comunidade como um todo, e não somente, indivíduos isoladamente.

Para os povos da floresta, uma reparação isolada, muitas vezes, não será suficiente para reestabelecer o direito violado, mas, ainda assim, constitui-se em um passo essencial para que exista a consolidação desses direitos, não podendo de nenhuma forma, vir a ser desprezada.

Compreende-se nesse sentido que: “"[...] reparações para as pretensões indígenas parecem caras, mas, elas valem o que custam. Elas precisam ser vistas não como um custo a ser pago, mas como um investimento para o futuro de todo país"” (LENZERINI, 2008). ${ }^{12}$

\footnotetext{
${ }^{11}$ Compreensão apresentada por Oswaldo Ruiz Chiriboga e Gina Donoso na obra "Pueblos Indígenas y la Corte Interamericana: Fondos y Reparaciones" do ano de 2012.

${ }^{12}$ Do original: “[...]'| $\mathrm{r}$ | eparations for indigenous grievances look expensive but are well worth it. They need to be seen, not as a cost to be borne, bus as an investment for the future of the whole country."'. Tradução livre.
} 


\section{ETNODESENVOLVIMENTO COMO FERRAMENTA DE PROTEÇÃO DE COMUNIDADES TRADICIONAIS}

No âmbito das discussões do campo acadêmico "Direito e Desenvolvimento", Davis e Trebilcock $^{13}$ apresentam a importância que as instituições jurídicas possuem na busca pela melhoria da situação dos países em desenvolvimento. Assim como as instituições nacionais possuem efeito sobre o bem-estar da população, as instituições internacionais também podem assumir as mesmas funções, ao impulsionarem o crescimento nacional e ao influenciarem a regulação do direito nacional.

O sistema jurídico internacional terá, então, importância na promoção do desenvolvimento a partir do momento em reformas jurídicas realizadas no âmbito internacional acabam por impactar diretamente no conteúdo a ser apresentado pelo direito nacional. Um exemplo são as reformas realizadas no âmbito do direito econômico internacional. Por terem efeitos potenciais no comércio e em investimentos internacionais afetam por tabela os preços enfrentados por consumidores locais, oportunidades para produtores locais e os incentivos que estes poderão vir a receber.

É nesse sentido, que o direito internacional também influencia no desenvolvimento de comunidades locais pelas mais diferentes perspectivas. A promoção do etnodesenvolvimento pode ser apresentada nesse trabalho como uma forma de promoção da relação entre direito e desenvolvimento, ao passo que permite a integração de concepções de um desenvolvimento econômico, que é necessário, com as necessidades de proteção ambiental, social e cultural que as pessoas diretamente afetadas por estes projetos de desenvolvimento precisam ter salvaguardadas.

Inegável que construções como direito de desenvolvimento e direito ao desenvolvimento, bem como, desenvolvimento econômico, desenvolvimento sustentável, ou ainda, etnodesenvolvimento, são conceitos que podem ser encontrados, se não diretamente, serão decorrentes de uma construção acadêmica, nesse contexto de formação e aceitação de existência de "Regimes Internacionais no Contexto do Desenvolvimento".

Da necessidade de se proceder com a distinção entre as noções de Direito Internacional do Desenvolvimento e Direito Internacional ao desenvolvimento, foi possível empreender que no campo do direito internacional, e seus regimes jurídicos, o emprego da preposição “do" e

\footnotetext{
${ }^{13}$ Kevin Davis e Michael Tribilcock reforçam a importância das instituições tanto nacionais quanto internacionais, ao mencionarem os trabalhos de Carothers e Dam, bem como Trubek e Santos, na busca pela definição de uma relação entre o direito e o desenvolvimento.
} 
"ao" quando se tem como objetivo expressar o desenvolvimento, pode apresentar duas situações, com contextos históricos, objetivos, e porque não dizer, sujeitos um tanto quanto diferenciados.

Enquanto o direito ao desenvolvimento compreende a parte do direito que é a responsável pela elaboração de normas e instituições jurídicas voltadas para a promoção do desenvolvimento. $\mathrm{O}$ direito internacional do desenvolvimento revela-se como uma temática extremamente complexa.

Em uma concepção elaborada em torno de 1974, procurava-se garantir o Direito do Desenvolvimento através da adoção de uma natureza intervencionista, que buscava o estabelecimento de uma "Nova Ordem Internacional Econômica", com o objetivo de: “[...] eliminar a crescente brecha entre os países desenvolvidos e os em desenvolvimento e garantir uma constante aceleração econômica e desenvolvimento social e paz e justiça para as presentes e futuras gerações [...]”14 (Declaration on the Establishment of a New International Economic Order).

Em uma visão contemporânea, a noção do Direito do Desenvolvimento se apresenta agora em documentos como a Declaração do Milênio, na qual, considerando as dificuldades que países em desenvolvimento e países com economias de transição enfrentam, busca-se através da conjugação de esforços, amplos e sustentados, a criação de um futuro comum, incluindo a “adoção de políticas e medidas, a nível mundial, que correspondam às necessidades dos países em desenvolvimento e das economias em transição e que sejam formuladas e aplicadas com a sua participação."

A corrida pelo desenvolvimento torna-se, então, extremamente relevante no contexto global, e a inserção do Brasil, como um país em desenvolvimento nesse contexto, reforça a necessidade de que o mesmo passe agora a assumir a responsabilidade de cumprimento dos Objetivos do Milênio, como por exemplo a garantia de uma sustentabilidade ambiental.

O foco de atenção do presente artigo, não se encontra, contudo, na promoção do direito do desenvolvimento. $\mathrm{O}$ que se pretende garantir para as comunidades indígenas é a salvaguarda dos seus direitos ao desenvolvimento, bem como, compreender de que forma os padrões de desenvolvimento que foram adotados nacionalmente afetaram esses povos.

\footnotetext{
${ }^{14}$ Do original: "[...] eliminate the widening gap between the developed and the developing countries and ensure steadily accelarating economic and social development and peace and justice for presente and future generations [...]” (Declaration on the Establishment of a New International Economic Order). Tradução livre.
} 
Para os povos indígenas, o direito ao desenvolvimento está atrelado não só a noção de desenvolvimento sustentável, que é muito explorada pelo Direito Internacional Ambiental. Inclui-se aqui também:

[...] a noção de etnodesenvolvimento indígena como um contraposto alternativo as teorias e ações desenvolvimentistas, que consideravam as comunidades tradicionais como osbstáculos ao desenvolvimento. Adotou-se como objetivo a criação de um modelo de desenvolvimento alternativo, que superasse o fracasso do modelo de desenvolvimento econômico, tendo em vista, que este, diante da diversidade dos países, demonstrou-se um modelo ineficaz para a garantia do desenvolvimento das minorias, considerando seus fatores étnicos. O poder decisório é deslocado para a sociedade civil, em contraposição ao modelo tradicional de desenvolvimento, que estabelecia um desenvolvimento de base, sendo feito de cima para baixo. As comunidades, antes marginalizadas, assumem o papel de sujeitos do desenvolvimento. Esse é agora o marco para a determinação das políticas públicas de desenvolvimento, a nível nacional e internacional. (SILVA, 2013, p. 36)

O desenvolvimento, em sua perspectiva de um direito inalienável, garantido a todos os seres humanos, que poderão participar e gozar do desenvolvimento econômico, social, cultural e político, e ter uma plena realização de seus direitos e garantias fundamentais, apresentado na Declaração sobre o Direito ao Desenvolvimento em 1986, amplia-se no contexto de um direito internacional globalizado. Atualmente, as atividades desenvolvimentistas passam a ter o dever de compatibilizar os âmbitos: econômico, social, cultural e ambiental. Trata-se da garantia do direito de conservação (proteção e evolução), direito de informação, bem como, do direito de participação na tomada de decisões.

Ressalta-se que, ainda que o modelo de desenvolvimento sustentável, considerado como aquele deve ser adotado, melhore o padrão de crescimento adotado aperfeiçoando a forma de manejo de recursos sociais e ambientais, não significa que necessariamente há uma melhoria na participação política e social dos demais povos, ou seja, não se adotou como objetivo desse desenvolvimento a formação de uma ordem social mais justa e equitativa.

O que busca através dessa compreensão é que a garantia dos direitos fundamentais e humanos dos povos indígenas sejam respeitados em um contexto de desenvolvimento. Seja, garantindo um desenvolvimento econômico, pautado nas noções de um desenvolvimento sustendo que concilie o social, o econômico e o ambiental; ou, na forma de um etnodesenvolvimento, em que se permite o desenvolvimento integrado das comunidades indígenas, que possuem uma concepção completamente diferenciada de mundo.

Este discurso precisa estar, ainda, alinhado com o conhecimento de que o etnodesenvolvimento não possui apenas um viés. Além de compreender o desenvolvimento 
econômico de um grupo étnico, ele também busca garantir o desenvolvimento da etnicidade de um grupo social. Deste modo, ao mesmo tempo em que se reforça a autonomia cultural de um grupo étnico, há a busca pela integração desse grupo a estrutura da economia, seja ela nacional ou internacional, considerando que a interdependência mundial impede que as comunidades locais se mantenham totalmente desvinculadas do restante da sociedade global.

Este modelo de desenvolvimento possui um impacto no aspecto político, quando "[...] dá um recorte étnico aos debates sobre a questão da autodeterminação dos povos, e no, processo, questiona, pelo menos parcialmente, as noções excludentes de soberania nacional" (LITTLE, 2013, p. 40). Busca assim, afastar a tradicional noção de que os povos tradicionais são empecilhos ao desenvolvimento, sendo, portanto, considerados como não "modernos", abandonando ainda, a noção de desenvolvimento que não considerava a existência de etnias diferenciadas.

No plano econômico, há um impacto quando se criam alternativas de crescimento econômico, adequadas a realidade pluriétnica. Abandona-se aqui, a noção de "desenvolvimento por pilhagem", que consistia na retirada de recursos de uma determinada região, voltando-os para a exportação, deixando para a área somente os impactos negativos, remanescentes da exploração.

Há ainda, o impacto do etnodesenvolvimento no aspecto simbólico, pois, reafirma-se a necessidade de proteção da propriedade intelectual das comunidades tradicionais, que possuem tradições e técnicas únicas, que ditam de que maneira a relação (harmônica e não destruidora) se dará com a natureza.

Ainda assim, é preciso que se questione um ponto determinante: o etnodesenvolvimento é um direito subjetivo das comunidades indígenas? Considerando a atual tendência de expansão dos direitos que estão relacionados ao desenvolvimento, os povos indígenas passam a ser incluídos na categoria de sujeitos de direito, inclusive de direitos de natureza coletiva. Garantese, portanto, a eles, o direito de desenvolvimento.

Stavenhagen determina ainda, que coube a Declaração das Nações Unidas sobre os Direitos dos Povos Indígenas estabelecer um marco normativo acerca do direito ao desenvolvimento dos povos indígenas, estabelecendo como bases os princípios de livre determinação, consentimento livre, prévio e informado, efetiva participação, autonomia, autogestão e não discriminação (STAVENHAGEN, [s.d], p.157).

O direito ao etnodesenvolvimento pode, então, ser considerado como um objeto de direito ou como uma decorrência do direito de desenvolvimento. Conforme Anjos Filho, existe 
um direito ao desenvolvimento que é próprio das comunidades indígenas, constituindo-se assim, em uma expressão jurídica de etnodesenvolvimento (ANJOS FILHO, 2012, p. 17).

\section{CONCLUSÃO}

Verifica-se que o universo normativo e institucional no qual o Direito Internacional irá atuar deverá ser compreendido como fragmentado e marcado por um pluralismo jurídico. E mais, o desenvolvimento na sociedade internacional, e, por conseguinte, na sociedade nacional está diretamente relacionado com o Direito e sua capacidade de contribuição através de corpos especializados e esquemas de regulação.

Dentre as temáticas apresentadas, que de maneira ampla passaram pelo Direito Internacional Público e sua fragmentação em regimes conhecidos como "self-contained regimes"; pelo Direito Internacional do Desenvolvimento, e seu desdobramento no Direito Internacional ao Desenvolvimento; bem como, pelo Direito Internacional do Meio Ambiente e a relação entre o Direito Internacional com o ordenamento jurídico interno dos países, procurouse demonstrar como as questões pertinentes a povos indígenas, abarcam, diante de um processo de fragmentação do direito internacional, disposições tanto do direito internacional ambiental como dos direitos humanos.

Para tanto, se lançou-se mão do uso de algumas situações ilustrativas, como a construção de uma Usina Hidroelétrica, representada nesse artigo pela UHE de Belo Monte. Tal emprego procurou demonstrar que o ordenamento jurídico brasileiro precisa se preparar para lidar com a existência de diferentes regimes jurídicos do direito internacional, capazes de apresentarem leis especiais sobre temas específicos, como a proteção ambiental e a garantia de direitos humanos, aplicáveis aos povos da floresta.

É, portanto, com base no exposto, que se compreende que o estudo dessa temática requer, conhecimentos interdisciplinares, capazes de demonstrarem que os mais variados regimes jurídicos oriundos do processo de fragmentação são aplicáveis na proteção das comunidades tradicionais indígenas. Não se limitando aqui, aos regimes apresentados pelo direito ambiental internacional e os direitos humanos. 


\section{REFERÊNCIAS}

BRASIL. Decreto Lei n. 143, de 20 de junho de 2002. Aprova o texto da Convenção n. 169 da Organização Internacional do Trabalho sobre os povos indígenas e tribais em países independentes. Diário Oficial [da] República Federativa do Brasil, Brasília, DF, 2002. Disponível em: <http://6ccr.pgr.mpf.gov.br>. Acesso em: 28 mar. 2016.

CBD. Akwé: Kon: Voluntary Guidelines for the Conduct of Cultural, Environmental and Social Impact Assessment regarding Developments Proposed to Take Place on, or which are Likely to Impact on, Sacred Sites and on Lands and Waters Traditionally Occupied or Used by Indigenous and Local Communities. Montreal: Secretariat of the Convention on Biological Diversity, 2004. Disponível em: <http://www.cbd.int>. Acesso em: 28 mar. 2016.

CHIRIBOGA, Oswaldo Ruiz; DONOSO, Gina. Pueblos Indígenas y la Corte Interamericana: Fondos y Reparaciones. Bélgica: Corte Interamericana de Direitos Humanos, 2012. Disponível em: <http://www.corteidh.or.cr>. Acesso em: 05 mar. 2016.

COSTA RICA. Corte Interamericana de Direitos Humanos. Caso da Comunidade Moiwana vs. Suriname. Preliminares, Mérito, Reparação e Custas. Julgamento em 15 de junho de 2005. Disponível em: <http://www.corteidh.or.cr>. Acesso em: 28 mar. 2016.

LENZERINI, Federico (Coord.). Reparations for indigenous peoples: international and comparative perspectives. London: Oxford University Press, 2008. Disponível em: <http://www.corteidh.or.cr>. Acesso em: 28 mar. 2016.

NASSER, Salem Hikmat. Desenvolvimento, Costume Internacional e Soft Law. [S.1]: [s.n], [s.d].

; REI, Fernando (organizadores). Direito internacional do Meio Ambiente. São Paulo: Atlas, 2006.

. O direito global em pedaços: regimes, fragmentação e pluralismo. [S.1]: [s.n], 2014.

ONU. Declaração do Milênio. Nova Iorque: Cimeira do Milénio, 2000. Disponível em: <https://www.unric.org>. Acesso em: 13 mar. 2016.

Fragmentation of International Law: difficulties arising from the diversification and expansion of International Law. A/CN.4/L.702. 18 jul. 2006, p. 3, par. 6. Disponível em: <http://www.un.org>. Acesso em: 13 mar. 2016.

. Resolutions adopted on the report of the ad hoc committee of the sixth special session. Disponível em: <http://www.cetim.ch/>. Acesso em: 13 mar. 2016.

. World Charter for Nature. [S.1]: A/RES/37/7, 1982. Disponível em:

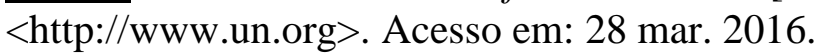

ORGANIZAÇÃO DOS ESTADOS AMERICANOS. Derechos de los pueblos indígenas y tribales sobre sus tierras ancestrales y recursos naturales: normas y jurisprudencia del Sistema 
Interamericano de derechos humanos. [S.1]: OEA, Ser. L, v. II, Doc. 56/09, 2010-1. Disponível em: <http://www.cidh.org>. Acesso em: 28 mar. 20156

Indigenous and tribal people's rights over their ancestral lands and natural resources: norms and jurisprudence of the Inter-American Human Rights System. [S.1]: OEA, Ser. L, v. II, Doc. 56/09, 2010-2. Disponível em: 〈http://www.cidh.org〉. Acesso em: 28 mar. 2016.

Projeto de Declaração Americana sobre os Direitos dos Povos Indígenas: Seventh meeting of negotiations in the quest for points of consensus. Brasília, Working Group to Prepare the American Declaration on the Rights of Indigenous Peoples, 2006. Disponível em: <http://www1.umn.edu >. Acesso em: 28 mar. 2016.

PIOVESAN, Flávia. Direitos humanos e direito constitucional. São Paulo: Saraiva, 2013.

SILVA, Janaina Nascimento. CRITÉRIOS INTERNACIONAIS DE PROTEÇÃO E REPARAÇÃO DE COMUNIDADES INDÍGENAS: a violação do direito de propriedade indígena no Brasil. 2013. Monografia - (Bacharelado em Direito) - Centro Universitário do Estado do Pará, Belém. 2013.

SIMMA, Bruno; PULKOWSKI, Dirk. Of planets and the universe: self-contained regimes in international law. EIJIL, 2006, vol, 17, n. 3. Disponível em: <http://www.ejil.org>. Acesso em: 28 mar. 2016.

SOUSA, Cássio Noronha Inglez de. Perspectiva indígena sobre projetos, desenvolvimento e povos indígenas: entrevista com Valéria Paye Pereira Kaxuyana e Euclides Pereira Macuxi. In: . Povos indígenas: projetos e desenvolvimento II. Brasília: Paralelo 15, 2010.

STAVENHAGEN, Rodolfo. Los Pueblos Indigenas y sus derechos. México: UNESCO, [s.d]. Disponível em: < http://www.cinu.org.mx>. Acesso em: 29 mar. 2016

TRINDADE, Antonio Augusto Cançado. Environment and Development: Formulation and implementation of the Right to Development as a Human Right. In: Trindade, Antonio Augusto Cançado. Derechos humanos, desarrollo sustentable y meio ambiente. San Jose da Costa Rica: Instituto Interamericano de Derechos Humanos, 1992.

TWINING, William. Implications of "globalisation" for law as a discipline. [S.1]: [s.n], [s.d].

VARELLA, Marcelo D. Direito internacional público. São Paulo: Saraiva, 2012. 